\title{
The Medical Library Is History
}

Medical libraries are dying. Or at least some specific sorts of medical librariesindependent institutional libraries, owned by historic organizations, in historic buildings, with large historic collections - are under serious threat of themselves becoming part of the past. To mitigate this threat, there is a need to rethink the nature of the "historic" medical library. This involves reconsidering the library's relationship to medicine and the history of medicine as disciplines, defining what is important about the nature of the library as a physical space and of its collections as material things, and reevaluating its audiences. Digitization has a role to play in this rethinking, but it is neither a panacea nor, in most cases, does it address fundamental questions about the sustainability and utility of legacy print collections and the spaces used to house them. Drawing on experiences of working with museum and library collections in two "independent" institutions - the Royal College of Surgeons of England and the Wellcome Trust - this essay considers what such a rethinking might look like in practice.

\section{Defining the Challenge}

What are the challenges? First, libraries are moving to a model in which a large and increasing amount of biomedical literature is delivered electronically rather than in print. ${ }^{2}$ In an ideal world, such a shift would be accompanied by the extra resourcing needed to develop and operate digital delivery while protecting the (sometimes slightly, sometimes very) different resource requirements for managing physical holdings. In practice this is rarely the case, and librarians are required to prioritize resource allocation - a requirement that has only become more acute in the aftermath of the recent global economic downturn. ${ }^{3}$ Second, in a digital information environment, as in the physical world, scale brings economies. A shift to digital delivery

1. The author is grateful to George Wohlreich, Robert Hicks, and Michelle DiMeo for their kind invitation to present at the symposium celebrating the 225th Anniversary of the Historical Medical Library of The College of Physicians of Philadelphia, and to Jeffrey Reznick and Michelle DiMeo for their comments on an early draft of this essay. CSimon Chaplin, Attribution 4.0 International (https:// creativecommons.org/licenses/by/4.0/) CC BY 4.0.

2. Lawrence Hunter and K. Bretonnel Cohen, "Biomedical Language Processing: Perspective What's Beyond PubMed?” Molecular Cell 21, no. 5 (Mar. 2006): 589-94.

3. Research Information Network, "Challenges for Academic Libraries in Difficult Economic Times: A Guide for Senior Institutional Managers and Policy Makers," available online at http:/ /www.rin. ac.uk/system/files/attachments/Challenges-for-libraries-FINAL-March10.pdf [accessed April 25, 2014]. 
is challenging, but it is especially so for smaller institutions that may have a lower resource base (making it harder to redistribute costs) and/or lack technical expertise and infrastructure (meaning that willingness to change is hampered by inability to actually deliver). Third, while it might seem that the response to the first two challenges is simply to digitize collections (thus once again bringing delivery of historic and current resources into alignment), there are a number of obstacles. They include (most obviously) the cost of digitization but also the fact that physical condition and rights may inhibit digitization, or at least distribution of digitized content, and that delivery of digital content acquired via subscription and that of digitized content created from an institution's own holdings actually require very different processes. ${ }^{4}$

\section{Why Is Medicine a Special Case?}

These consequences of irresistible change bear heavily on all libraries, but especially on medical libraries. This is partly because of the nature of medicine, at least within the western tradition (a phrase that in itself denotes the importance attached to concepts of heritage and history in medical practice). ${ }^{5}$ The relationship between medicine and its past has not simply been a matter of disinterested inquiry; rather, it has placed particular emphasis on the establishment of lineages of theory and practice and the creation of narratives of (ideally progressive) continuity. As the hematologist-turned-historian of medicine Jacalyn Duffin notes, the tendency to describe historical events in the light of present knowledge, and to valorize those aspects that appear congruent with what we think now, is an especially hard habit to shake for clinicians, who must have faith in their own beliefs about what is best for a patient. ${ }^{6}$ Even novel medical specialties rapidly acquire (or rather, have manufactured for them) "prehistories" that predate their definition in medical theory or practice. ${ }^{7}$ Not surprisingly, such histories are heavily predicated on evidence drawn from the corpus of medical literature. Two examples may illustrate the general point. In 1959, Arno Motulsky was busy building a new division of medical genetics (itself then a new specialty) at the University of Washington when he published his account of the British physician Joseph Adams (1756-1818), describing him as a "forgotten founder" of Motulsky's own field through his authorship of A Treatise on Supposed Hereditary Properties of Disease (1814). ${ }^{8}$ More recently, a joint project led

4. For a survey of the challenges facing libraries see Marilyn Deegan and Simon Tanner, Digital Futures: Strategies for the Information Age (London: Facet, 2013).

5. The use of the term "tradition" does not, of course, reflect stasis. See Lawrence I. Conrad et al., The Western Medical Tradition, 800 B.C. to A.D. 1800 (Cambridge: Cambridge University Press, 1995); and W.F. Bynum et al., The Western Medical Tradition: 1800 to 2000 (Cambridge: Cambridge University Press, 2006).

6. See Jacalyn Duffin, History of Medicine: A Scandalously Short Introduction, 2nd ed., (Toronto: University of Toronto Press, 2010), 444-45.

7. On medicine's ability to construct tradition, see Stephen Jacyna, "Medicine in Transformation, 1800-1849," in The Western Medical Tradition, W.F. Bynum et al., 11-110.

8. Arno Motulsky, "Joseph Adams (1756-1818): A Forgotten Founder of Medical Genetics," AMA Archives of Internal Medicine 104, no. 3 (1959): 490-96. 
by Sir Iain Chalmers (one of the founders of the Cochrane Collaboration, which provides systematic reviews of randomized controlled trials in health care) has led to the creation of the James Lind Library, an online resource that illustrates the development of "fair tests" in medicine and that includes extracts of texts dating over three thousand years. ${ }^{9}$ My point here is not to take issue with this particular historiographical tendency (which has been largely superseded among professional historians of medicine and, to a lesser extent, within the community of clinicianhistorians, by approaches derived from social, cultural, and economic history; the history of ideas and the sociology of knowledge and the fields of visual and material culture) ${ }^{10}$ Rather, it is to emphasize how important history has been, and remains, to medical practitioners and the reliance it has placed on historic medical texts.

This tendency to historicize and place emphasis on textual precursors has had one particular consequence for medical libraries: namely, that many possess collections of books and other items that predate their foundation. Medicine has a long literary tradition that has resulted in a vast - and growing - textual corpus. Holding physical copies of books and journals considered "seminal" has therefore been one way in which medical practitioners and institutions have made manifest their connections with the past. The giving of rare books to libraries, and the pursuit of active programs of acquisition by libraries, both largely driven by the bibliohistorical interests of medical practitioners, means that it is not unusual to find a library founded in the early 1900 s that possesses books dating back to the invention of printing some four and a half centuries earlier. The same is true of journal literature: the acquisition of retrospective print runs of core titles such as Lancet or the New England Journal of Medicine would have been seen as a natural act for a newly created medical library even a half century ago (and, like book collecting, would have been possible because of the existence of bound runs in private hands). The physical spaces holding these collections-library reading rooms - have therefore been imbued with symbolic status that transcends their functional role as places for study. Indeed, for many medical institutions, it was the need to have a place to hold and consult collections of books and journals that provided the rationale for their creation as physical, rather than merely social, structures. ${ }^{11}$

All of this means that the shift from print to digital is more problematic for medical libraries than it might otherwise be due to the volume of their legacy print holdings and the status accorded to (at least parts of) them by virtue of being "historical." The problem is true for all medical libraries with historic collections, but it is felt less obviously

9. The James Lind Library, available online at http://www.jameslindlibrary.org/ [accessed June 21, 2014].

10. For a concise summary of trends in medical historiography since the mid-20th century, see Keir Waddington, An Introduction to the Social History of Medicine (London: Palgrave Macmillan, 2011), 1-15.

11. See, for example, Michael Brown, Performing Medicine: Medical Culture and Identity in Provincial England, c.1760-1850 (Manchester: Manchester University Press, 2011), 158-60. 
in a university context (and in the United Kingdom at least, major teaching hospitals are now affiliated with universities through their medical schools). In a university, there is more often scope for absorbing historic medical collections into general university library special collections, and differentiating services to readers according to level of interest (undergraduate/postgraduate/postdoctoral) across a range of disciplines. This may represent an unduly rosy picture of university life, but it is nevertheless reasonable to suggest that the problems are much more acute for those libraries within more venerable independent medical institutions - venerable, in this case, suggesting a foundation date of 1950 or before. Such institutions are usually supported through a membership model (either purely voluntary, as with a local medical society, or linked to professional regulation/qualification, as with British and Irish medical royal colleges). Their user community is usually geographically dispersed (in contrast to a university campus library). They tend to occupy historic buildings. Last—and primarily as a consequence of the above- they commonly operate within tight space, staff, and financial resource constraints. For most of these institutions, the library was (and may still be) part of the membership offer, facilitating access to current medical literature for practitioners. Here the problem of the bifurcation of delivery methods comes into play; and, with a finite resource base, librarians rarely have the luxury of being able to develop a comprehensive electronic resource collection while maintaining the same level of investment in the care and management of legacy print collections. ${ }^{12}$

\section{Some Responses-Go Modern, or Sell Off}

An example of an organization that has chosen to prioritize current information resources over heritage collections is the Royal Society of Medicine (RSM). Founded as the Medical and Chirurgical Society of London in 1805, it became the RSM in 1907 when it incorporated seventeen other specialist medical societies (a move instigated by its Secretary, and former Librarian, Sir John MacAlister). ${ }^{13}$ The RSM's library holds a fine collection of rare books, journals and archive material. However, following a strategic review in 2012, driven in part by the Society's need to "sweat its assets" in order to ensure its financial sustainability, the library's primary focus is now firmly fixed on delivering electronic information services, something that features heavily in the RSM's marketing. ${ }^{14}$

12. Alex Stutz, "Mapping Medicine: Collaborative Collection Management for Biomedical Resources. Review of the literature," Health Information \& Libraries Journal 19, no. 4 (Dec. 2002): 226-29.

13. Penelope Hunting, The History of the Royal Society of Medicine (London: Royal Society of Medicine, 2002).

14. For example, the RSM "Members" website begins "Your Membership, your benefits, your web resources" followed by "Access to 7 major medical databases online." The Royal Society of Medicine, available online at http:/ / web.archive.org/web/20140214143647/http://www.rsm.ac.uk/members/ [accessed September 30, 2014]. The RSM Library strategy and supporting documents are available online at https://www.rsm.ac.uk/library/library-strategy.aspx [accessed September 30, 2014]. The reference to "sweating its assets" comes from the Library Services Review Group Report, 30, available online at https: / / www.rsm.ac.uk/media/199259/library_report.pdf [accessed June 23, 2014]. 
Yet the RSM still looks after its rare books and archives. The same cannot be said of the Medical Society of London, which sold its collection to the Wellcome Library in the 1980s, or the Birmingham Medical Institute (founded as a medical library in 1875), which auctioned off its entire rare book and manuscript collection—containing a great many works with authorship or provenance links to the city-in order to meet a shortfall in revenue arising from falling demand for its continuing professional education courses. ${ }^{15}$

\section{From Historic Medical Library to Library for the History of Medicine}

The RSM experience suggests that, in pursuit of income, the best that a historic book collection can hope for is benign neglect; Birmingham, in contrast, represents the worst outcome. But is there a different way forward? How might medical libraries helpfully prioritize the "history" of their historic book collections and make them work more productively?

One answer - as adopted by the Semmelweis Library in Budapest - is to unashamedly rebrand as a library for the history of medicine. Formerly the library of the Royal Society of Physicians in Budapest, which was founded in 1837, it was redesignated as a national library and renamed the Semmelweis Library for the History of Medicine in 1964. Together with a museum and archive, it now serves a public, as well as an academic, audience, and is funded by the Hungarian government. ${ }^{16}$ But there are some caveats to this. The Semmelweis Library achieved the transition only because public funding was and is forthcoming to meet a perceived national or regional strategic need. Moreover, a historic medical library (or, rather, a medical library that is no longer current) is not the same thing as a library for the history of medicine. The Wellcome Library grew out of the library collection created by the pharmaceutical entrepreneur and philanthropist Henry Wellcome to support his ambitious Medical Historical Museum. ${ }^{17}$ As a result, its acquisition strategy has always included, and continues to include, comprehensive collecting of books, journals, databases, and moving image and sound records that are about the history of medicine, broadly conceived, as historical medical books. The development of the Wellcome Library has paralleled the emergence of medical

15. BBC News, Birmingham \& Black Country, "Birmingham Medical Institute to Sell 5,000-Book Library," available online at http:/ / www.bbc.co.uk/news/uk-england-birmingham-17733768 [accessed April 21, 2014]; Birmingham Mail, "Medical Books Sale Delivers Cash Boost for Birmingham Medical Institute, available online at http:/ / www.birminghammail.co.uk/news/local-news/medical-books-saledelivers-cash-189889 [accessed April 24, 2014].

16. Katalin Kaproncszay, "The Library of the Royal Society of Physicians in Budapest becomes today's Semmelweis Medical History Library," Journal of the Medical Library Association 99, no. 1 (Jan. 2011): 31-39.

17. History of the Wellcome Library, available online at http://wellcomelibrary.org/about-us/ history-of-wellcome-library/ [accessed April 21, 2014]. 
history as a full-fledged professional academic discipline, offering a range of methodological approaches to, and analytical insights into, the practices of medicine and healthcare in the past. A collection of medical books and journals is part of what such a library might need, but arguably it is not the most important part. In fact, becoming a history of medicine library is actually more complex than simply switching focus in terms of collecting activity. As a discipline, history of medicine is not neatly delineated. While there are a number of core journals, medical historiography can be found in a wide range of journals spanning science, medicine, social sciences, and the humanities. It is therefore easier to achieve in the context of a university, where a small core of history of medicine titles are supplemented by general holdings.

\section{From History of Medicine to Medical Humanities}

The distinction between the "historic medical library" and "library for the history of medicine" raises a further issue about disciplinary affiliation. Faced with the same situation now, would the Semmelweis Library for the History of Medicine instead opt to call itself a "library for the medical humanities"? The latter phrase describes the application to medicine of a group of disciplines in the humanities and, to a lesser extent, the arts and social sciences. History of medicine forms part of this constellation, but only part. Yet, in some senses, the objectives of those working in the medical humanities are rather similar to those espoused by earlier generations of medical historians. At a purely instrumental level, the inclusion of the humanities in the medical curriculum serves more or less the same aims espoused by William Osler a century ago, namely to produce medical practitioners whose horizons extended beyond the laboratory, clinic, or operating theatre..$^{18}$ Medical history has long performed this role, exposing medical practitioners and students to the past in ways that encourage them to be questioning and critical. But some see the potential for the medical humanities as going beyond this. The British philosophers of health Martyn Evans and David Greaves (who helped establish medical humanities as a distinct field in the United Kingdom in the late 1990s, some twenty years after it took root in U.S. medical curricula) have been influential in promulgating the idea that the humanities have the potential to reshape the nature of clinical medicine rather than simply "sensitizing" its practitioners. ${ }^{19}$ On the one hand, it offers some practical tools that can be tested in clinical practice, such as the idea of narrative medicine as a way of creating deeper patient-practitioner relationships. On the other, it has the potential to use the perspectives of artists, writers,

18. For a succinct description of Osler's aims, see William Osler, "A Note on the Teaching of the History of Medicine," British Medical Journal 2167, no. 2 (July 1902): 93.

19. See, for example, Martyn Evans and David Greaves, "Exploring the Medical Humanities," BMJ 319, no. 7219 (Nov. 6, 1999): 1216. 
philosophers, and musicians (to name but a few) to create more sophisticated critiques of medicine. ${ }^{20}$

\section{Materiality, Audiences, and Space}

One consequence of thinking about the ways in which a historic medical library might respond to the wider medical humanities agenda is to bring to the fore questions of materiality and audience. An often-made argument in favor of preservation of physical collections is that books possess value as material artifacts. Sometimes this is articulated in terms of singularity: particularly for early printed books, there is an argument that there is no such thing as an "identical" copy. By eliminating physical collections in favor of a common digitized resource that avoids wasteful duplication, the risk is that we (to borrow a biological analogy) depopulate the gene pool and lose evidence of variation. ${ }^{21}$

Another argument is that, while digital facsimile can retain at least some of the informational qualities of a book, it loses the essential user experience - that books were designed to be handled, and that the absence of handling therefore significantly diminishes our understanding of their role (much as watching a recording of video game footage provides only the barest insight into the experience of game play, or reading a musical score does of a live performance). There are other academic disciplines - art history, archaeology, anthropology, and ethnography, for example - that privilege the epistemological potential of the materiality of objects much more effectively. Opening up library collections to the insights that these disciplines may bring does require the real things to be available. Moreover, it also encourages a focus on how the outputs of such investigations might be presented, and to whom. Here, libraries can usefully borrow from museum practices of collection-centered research, interpretation, and engagement while still emphasizing the qualities - accessibility, interactivity, community connections - that are their traditional strengths. ${ }^{22}$

The third corner of a triangle connecting collection and audience is space. Most libraries in the kinds of institutions we are talking about here were designed with a very specific model of audience engagement, namely that of relatively large

20. Wellcome Trust, Funding, Medical Humanities, available online at http://www.wellcome. ac.uk/Funding/Medical-humanities/ [accessed April 21, 2014]. The Wellcome Trust uses a definition of "medical humanities" that extends beyond the application of humanities (and arts) approaches to effect change in medical education or practice, as described in, for example, Medical Education: A Practical Introduction, eds. Deborah Kirklin and Ruth Richardson (London: Royal College of Physicians, 2002).

21. The Economist, Babbage, Science and Technology, Book Digitisation: More Than Just Text, available online at http:/ / www.economist.com/blogs/babbage/2012/05/book-digitisation [accessed April $21,2014]$.

22. See, for example, Elaine Heumann Gurian, “Museum as Soup Kitchen,” Curator 53, no. 1 (Jan. 2010): 71-85. 
numbers of individuals consulting printed books and journals. In this model, engagement is solitary and silent, facilitated by the availability of large quantities of material on open shelves. To maximize natural light, such spaces tended to be large and often galleried and top-lit. ${ }^{23}$

These kinds of reading rooms (familiar to all users of historic libraries) have their limitations. They are unsuited to some emergent models of user behavior, such as social working. They have also been hard to retrofit for delivery of electronic resources (though with the advent of Wi-Fi and bring-your-own-device delivery models, this particular limitation has been lifted somewhat). More commonly, as a greater proportion of users access content online from their own desks, the need to use the library has simply decreased. Many traditional reading rooms are empty for much of the time. ${ }^{24}$

\section{The Library as Museum}

So how does the idea of a library-as-museum aid a rethinking of the role of library collections and spaces for new audiences? One option, of course, is simply to displace, and to take advantage of, the reading room's architectural features for straightforward museum display. The Grant Museum of Zoology at University College London is a good example of an academic museum collection (of comparative anatomy specimens) being rehoused in a former medical library and, so doing, gaining greater public visibility (which supports the parent institution's marketing and public engagement goals) while also making it more accessible for teaching and research (addressing immediate departmental priorities). ${ }^{25}$

There is also a more profound way in which the display of quasimedical collections such as those of the Grant, or fully medical ones such as those of the Hunterian Museum at the Royal College of Surgeons of England (which houses the anatomy and pathology specimens belonging to eighteenth-century surgeon John Hunter) might inform the debate about medical libraries. Biological and medical specimen collections are not dissimilar to rare book collections in being both cherished (for their past uses and associations) and resented (for their occupation of space that might otherwise be used for laboratories or seminar rooms and for consuming staff time and money to maintain in the face of dwindling didactic or research use). The redisplay of the Hunterian Museum in 2005-for which the author was one of the lead curators-involved taking a tired and little-used collection and representing it to

23. James Campbell, The Library: A World History (London: Thames \& Hudson, 2013).

24. For some users, this is a plus: see Fat Ponies, St. Barts Library: A Quiet Place to Write in London, available online at http: / / www.fatponies.com/2012/05 / 19/st-barts-library-a-quiet-place-to-write-inlondon/ [accessed April 24, 2014].

25. Joe Cain, No Ordinary Space: Historical Notes on the Grant Museum of Zoology's New Home at University College London (STS Occasional Papers) (London: Euston Grove Press, 2011). 
a wide, public audience. The heart of the museum was a spectacular visual display of thousands of specimens linked to a new, but smaller, multipurpose space that could be used for teaching and research and that was open to the public when not being used. It was a success; the museum went from under ten thousand visits a year to over seventy thousand in the seven years after reopening. One of the qualities that made the museum a success was its emphasis on the specimens themselves, making them visible and - in appropriate contexts - touchable, and not only displaying them to a curious public audience but also demonstrating to such an audience how else they might be used in medical contexts rather than just treating them as curiosities. ${ }^{26}$

The success of the Hunterian Museum in attracting new audiences also prompted the college to look at how it might extend the same approach to its historic library. Dating back to its foundation in 1800, and containing a great many books and journals that predated this, the library was suffering from exactly the kinds of problems outlined at the start: a series of architecturally striking but mostly underused rooms for historic collections, a smaller and well-used modern resource center designed for surgical trainees, and a growing collection of electronic resources aimed at the college's membership of some ten thousand surgeons in the United Kingdom and overseas. A proposal was developed to link two of the smaller historic rooms to the museum, creating an extension to the permanent galleries space that would serve as a combined event and exhibition space for the historic books and archives, with a small study room available on demand to accommodate researchers wishing to use the collections. The main reading room was destined to become a corporate hire space, while acting as reserve storage for the nineteenth-century journals - essentially turning a nonproductive asset into a productive one. The aims were not only to make the collection more visible but also to make the concept of the library more visible to both corporate and public audiences. Like the Hunterian Museum, which offered free admission, there was no plan to derive immediate financial return from visitor charges, though such an approach might have been considered in other circumstances (much of the museum development cost came from public or external charitable funds).

\section{Beyond the Medical Humanities - A Library for the Incurably Curious}

The plans for the RCS Library did not come to pass: in 2009, the banking crisis forced the college to put on hold its development plans, and as of the appearance of this special issue they remain on hold, though not forgotten. However, the author's involvement in the project to rethink the role of the library helped to inform subsequent projects undertaken at the Wellcome Library. Unlike many medical

26. Fay Bound Alberti and Samuel J.M.M. Alberti, "The Hunterian Museum at the Royal College of Surgeons of England, London (review)," Bulletin of the History of Medicine 80, no. 3 (Fall 2006): 571-73. 
libraries, the Wellcome Library enjoys a degree of financial security thanks to the healthy state of its parent body, the Wellcome Trust. But, while it may have been shielded from financial pressures, it has-like the RCS library-been encouraged to think about the potential for new audiences as a result of the success of a linked museum project. In 2007, the building housing the Wellcome Library reopened as Wellcome Collection, a free "cultural destination" offering exhibitions and events that explore the intersection between medicine, life, and art for a "curious public" audience. Wellcome Collection's distinctive approach to exhibition making - it stages 2-3 major temporary shows a year, with two smaller permanent galleries taking a secondary role-has proved extremely successful, with the audience growing from the initial target of 100,000 visits a year to over half a million in just five years. ${ }^{27}$ Within Wellcome Collection, the Wellcome Library's audience has also grown to just over 40,000 visits a year, with an increasing number of these coming from nontraditional users (that is to say, not university students or faculty). But, overall, the launch of Wellcome Collection has failed to create a significant crossover between exhibition goers and library users.

The challenge, therefore, was to think about how this gap might be bridged, as part of a broader project that also involved creation of additional exhibition space, a workshop for young peoples' programs, and a restaurant. As a result, the historic galleried reading room, which previously formed part of the library, was redeveloped as a hybrid exhibition/event/library space (still called the Reading Room), which aimed to encourage visitors to linger at the end of their visit to explore a mixture of objects, books, moving image and sound files, and low-tech interactives and thus to delve a little deeper into some of the themes covered in the exhibitions. This new public Reading Room is intended to encourage the sharing of ideas through "pop-up" events (many led by visitors, rather than staff) and through the creation of a variety of places where visitors can leave their impressions for others to respond to, in the form of words or pictures. It will be accompanied by a lighttouch digital layer that exposes some of the library's digitized collections but, in response to audience research, will deliberately eschew the creation of a "virtual library"- there will be no touch screen interactives, and most users will engage with digital content, if at all, via their own devices. This is a deliberate play to one of the strengths of Wellcome Collection's curatorial approach, which is heavily object-centric. The Reading Room will contain examples of "gallery" objectsboth historical objects and artworks drawn from Henry Wellcome's collection, and pieces of contemporary art reflecting biomedical themes. Chosen primarily for their aesthetic impact and ability to provoke curiosity, they range from a mediaeval

27. Ken Arnold and Simon Chaplin, "Wellcome Collection and the Post-Medical Museum," in Medical Museums: Past, Present, Future, eds. Samuel J.M.M. Alberti and Elizabeth Hallam (London: The Royal College of Surgeons of England, 2012), 228-41. 
alchemist's furnace and a Pohl Omniskop x-ray apparatus from the early 1930s to a dress inspired by developmental biology by British artist Helen Storey and exquisite glass models of viruses and bacteria by sculptor Luke Jerram. But, in a nod to its library connections, the Reading Room will also emphasize the value of hands-on engagement. Vintage artifacts such as stereoscopes and microscopes will be on open shelves for visitors to use and explore for themselves. Digitization has been used as a step toward creation of high-end facsimiles of some of the Wellcome Library's rare books, manuscripts, and prints and drawings, which will be housed in solander boxes for users to rifle through or on open shelves with about a thousand other books chosen to illustrate different perspectives on the place of medicine in culture, past and present. By blending medicine, art, and history, offering opportunities to engage all the senses, and fostering interaction between and soliciting responses from visitors, the Reading Room is very much a library for the medical humanities in their broadest sense.

Time will tell whether the Reading Room taps into a hitherto unfulfilled desire on the part of audiences: like all bold experiments, there is an inherent risk of failure. Nor would this be a disaster: though clearly success is preferable, one of the values of the Wellcome Trust is that of taking risks and being innovative. But there are factors that have helped give confidence to this approach, aside from the Wellcome Trust's financial security. The first is location - the Reading Room is not buried within a campus or hidden behind security barriers. The second is audience: even before the redevelopment of the Wellcome Collection, the venue was attracting over 500,000 visits per annum, and it is intended to reach more than double this number by 2020. For the Wellcome Collection, the Reading Room represents an attempt to create a final link in the chain between exhibition space and library: in other circumstances, the former would represent a more obvious first step toward a public engagement model for a library collection.

\section{Conclusion}

This essay began by making the claim that some of our medical libraries are in danger of becoming history. There are enough examples of collections that have been sold or subsumed, and reading rooms that have been closed or partitioned into offices, to support this assertion. There are ways of breathing new life into these spaces and their associated collections, and these go far beyond the siren call of digitization or the optimistic rebranding of outdated medical collections as libraries for the history of medicine. This essay has suggested one approach, based on a broader concept of the medical humanities and public engagement, which has been inspired by a belief that the use of books for display and as information sources are not mutually exclusive-an approach to museum-making that is inspired by the historic strengths of the library, rather than the reverse. 